\title{
max \\ Trends in Cosmetics: Product Packaging at the Point of Sale
}

\author{
Belén Borja Guerrero, Aránzazu López Pecharromán and Rosario C. Sánchez León *
}

check for updates

Citation: Borja Guerrero, B.; López Pecharromán, A.; Sánchez León, R.C. Trends in Cosmetics: Product Packaging at the Point of Sale. Cosmetics 2022, 9, 27. https:// doi.org/10.3390/cosmetics9020027

Academic Editors: Carmen Garcia-Jares and Laura Rubio

Received: 13 January 2022

Accepted: 22 February 2022

Published: 24 February 2022

Publisher's Note: MDPI stays neutral with regard to jurisdictional claims in published maps and institutional affiliations.

Copyright: (C) 2022 by the authors. Licensee MDPI, Basel, Switzerland. This article is an open access article distributed under the terms and conditions of the Creative Commons Attribution (CC BY) license (https:// creativecommons.org/licenses/by/ $4.0 /)$.
Cosmetic Product Area, Medical Devices Department, Spanish Agency of Medicines and Medical Devices, 28022 Madrid, Sapin; bborja@aemps.es (B.B.G.); alopezp@aemps.es (A.L.P.)

* Correspondence: rsanchezl@aemps.es

\begin{abstract}
Recently, there has been a proliferation of establishments where cosmetics products are packaged at the purchaser's request, promoting the circular economy with the aim of reusing, recycling and reducing packaging. At the Spanish Agency of Medicines and Medical Devices (AEMPS, for its Spanish acronym), we asked ourselves whether this was a legal and safe practice. In order to verify this, a bibliographic analysis of the applicable legislation and regulations was carried out, and the conclusion reached was that it is legal practice, but a series of guidelines are necessary for it to be carried out with guarantees. Consequently, an instruction was developed which provides recommendations to ensure that the packaging of cosmetic products at the point of sale is carried out under optimum conditions. This instruction is aimed at both responsible persons and the personnel who carry out product packaging at the point of sale.
\end{abstract}

Keywords: sustainability; reuse; recycle; packaging; bulk; cosmetic; re-packaging; refill; filling station; AEMPS

\section{Introduction}

In recent times, the Spanish Agency of Medicines and Medical Devices (AEMPS, for its Spanish acronym) has observed the appearance and growth in the Spanish market of establishments that perform the packaging of cosmetic products at the point of sale in order to sell them on to consumers.

This activity is in line with the general trend observed in the cosmetics industry, focused on using more sustainable and environmentally friendly production processes. This promotes the circular economy, in keeping with the current European Union "3Rs" policy, namely, Reuse, Recycle and Reduce packaging.

Everyone uses many different cosmetic products every day. Some of these products could be susceptible of being packaged at the point of sale, for example, soaps, shampoos, perfumes, and shower gels, this activity is associated with the reutilization of the packaging what would mean a reduction of the number of containers used.

The AEMPS, as the competent Spanish authority for cosmetic products, wondered whether this was a legal activity, and if so, how it should be carried out, to ensure that the individual unit of sale purchased by consumers complied with European and Spanish legislation and were therefore safe for use.

In order to answer these questions, the Cosmetic Products Area at the AEMPS conducted a review of the current legislative texts applicable to cosmetic products in Europe and specifically in Spain. The conclusion it reached was that it is legal practice.

Additionally, the mentioned area is aware that the packaging of cosmetic products at the point of sale present some associated risks:

- the environmental conditions at the point of sale cannot be controlled like in the cosmetic products manufacturing facilities,

- the purchasers may try to use their own containers which would not be suitable for the product, 
- the traceability of the products from the original container to the individual unit of sale would be difficult to keep,

- etc.

In order to carry out this activity under optimal conditions, certain recommendations should be taken on board in order to reduce associated risks by maintaining the safety and product information guarantees after the product has been handled at the point of sale.

With the purpose of protecting the health of consumers and help to reduce packaging waste, enhancing sustainability and reducing environmental impact, the Cosmetic Products Area at the AEMPS, in collaboration with the Cosmetic Products Working Group of the Technical Inspection Committee (CTI in Spanish), drew up the "Instruction on the practice of packaging cosmetic products at the point of sale" [1]. It was approved by the CTI on 16 April 2021 and published on the AEMPS website on 21 April 2021. It is addressed to be followed by responsible persons, manufactures and personnel at the point of sale. The recommendations are the conclusion reached after a bibliographic review of the legal framework for cosmetic products at European and Spanish level on how all this normative could be implanted to the practice of packaging at the point of sale.

AEMPS presented the Instruction [1] to the European Competent Authorities at the 28 April 2021 plenary meeting of the Platform of European Market Surveillance Authorities for Cosmetics (PEMSAC) Group, and it became clear that this Instruction was the first document with recommendations published by a European-competent authority of cosmetic products on how to package cosmetic products at the point of sale.

This Instruction [1] would be a useful tool not only to the manufacturers of cosmetic products intended for packaging at the point of sale and to the personnel at the point of sale, but also to all citizens. It provides information that can help consumers to know what guaranties and information they should expect if they buy cosmetic products packaged at the point of sale.

\section{Materials and Methods}

First, in order to check whether the practice of packaging cosmetic products at the point of sale is in line with current legislation, a bibliographic review of the legal framework for cosmetic products at European and Spanish level was carried out:

- Regulation (EC) $N^{\circ} 1223 / 2009$ of the European Parliament and of the Council, of 30 November 2009, on cosmetic products [2]. (Regulation 1223/2009)

- Royal Legislative Decree 1/2015, of 24 July 2015, approving the revised text of the Law on guarantees and rational use of medicines and medical devices [3] (RDL 1/2015).

- Royal Decree 85/2018, of 23 February, regulating cosmetic products [4] (RD 85/2018)

The packaging of cosmetic products at the point of sale implies a number of associated risks, which need to be minimized in order to ensure the safe use of the products once they have been packaged at the point of sale.

This practice entails the handling of the cosmetic product intended for packaging (CPFP) at point-of-sale facilities, whose environmental conditions are not controlled in the same way that its manufacturing site conditions are.

Product packaging at the point of sale involves transferring the product from the initial packaging provided by the manufacturer to a different one. As a consequence, the product is exposed to the environment, which poses a risk of chemical and/or microbiological contamination. In addition, there is a risk of loss of information provided by the manufacturer, as the individual unit of sale is labeled on site.

Second, in order to determine the optimal conditions for point of sale product packaging, a review of all existing legislation and technical standards for cosmetic products manufacturing was carried out:

- Regulation (EC) No 1223/2009 of the European Parliament and of the Council of 30 November 2009 on cosmetic products [2].

- Royal Decree 85/2018 of 23 February 2018 regulating cosmetic products [4]. 
- Royal Legislative Decree 1/2015 of 24 July 2015, approving the revised text of the Law on guarantees and rational use of medicines and medical devices [3].

- UNE EN ISO 29621:2011 Cosmetics. Microbiology. Guidelines for risk assessment and identification of products with low microbiological risk [5].

- UNE-EN ISO 17516:2014 Microbiological limits in cosmetics [6].

- UNE-EN ISO 22716:2007 Cosmetic products. Best manufacturing practices. Best manufacturing practices guide [7].

Accordingly, the applicable legal framework and legal standards which are directly related to this activity and its security have been revised.

We have reviewed the AEMPS and the European Commission websites for checking this legal framework.

We have selected only the legal standards applicable to this activity, searching in the Spanish Standards and Certification Association (AENOR, for its Spanish acronym).

\section{Results}

Following a bibliographical review of the legal framework for cosmetic products at European and Spanish level, in order to find out whether product packaging at the point of sale is a practice in line with current legislation, the following results were obtained:

At the European level, Regulation 1223/2009 [2] establishes the legal framework for cosmetic products. Its article 19.4 states: "For cosmetic products that are not pre-packaged, are packaged at the point of sale at the purchaser's request, or are pre-packaged for immediate sale, Member States shall adopt detailed rules for indication of the information referred to in paragraph $1 "$.

Consequently, this Article applies to cosmetic products intended for packaging at the point of sale.

In Spain, no reference is made to this activity in RDL 1/2015 [3]. It appears in RD 85/2018 [4], article 27, which explicitly mentions establishments devoted to pack at the point of sale, stating:

1. "Establishments which package at the point of sale for sale at the purchaser's request cosmetic products intended by their manufacturer for such packaging at the point of sale, such as colognes and solid soaps, shall perform the packaging at the point of sale in accordance with the instructions and precautions indicated by the manufacturer.

2. These establishments shall be considered manufacturers or distributors, as the case may be, and shall assume all the obligations that, as such, correspond to them in the Regulation on cosmetic products and in this Royal Decree, and shall be subject to the supervision of the health authorities of the Autonomous Communities".

As a result, cosmetic product packaging at the point of sale is a practice that fits into the European and Spanish legal system.

Following a bibliographical review of all legislation and technical standards applicable to the manufacture of cosmetic products, recommendations have been developed for Responsible Persons and point of sale staff, to ensure that the packaging at the point of sale is carried out under optimal conditions, and that the individual unit of sale is ready for consumption and is safe for use.

\subsection{Recommendations to Be Considered by Responsible Persons}

\subsubsection{With Regard to Products}

We started from the premise that, in the case of in-store packaging at the point of sale, both CPFP and individual units of sale are considered finished products, in accordance with the provisions of Article 18.3.(a) of Regulation 1223/2009 [2].

Therefore, the Responsible Person, prior to their marketing, shall ensure compliance with all the requirements established in the aforementioned Regulation 1223/2009 [2], both in the case of the CPFP and in the case of the individual unit of sale. These include, among others, those relating to guarantees of information, identification, traceability and safety.

As a result, it is recommended: 
1. To include the following in the safety assessment established in article 10 of Regulation 1223/2009 [2]:

- $\quad$ Stability studies to certify the date of minimum durability of both the CPFP and the individual units of sale purchased by consumers.

- Instructions for handling CPFP at the point of sale.

- Labeling instructions for each individual unit of sale.

2. Provide instructions for point of sale staff, to enable them to carry out the appropriate portioning and product unit labeling. These instructions shall contain, as a minimum, the following information:

- $\quad$ Storage conditions.

- Dosage system cleaning and maintenance instructions.

- Hygiene rules.

- Handling conditions.

- Prohibition of transferring the cosmetic to a container different than the individual unit of sale one.

- Prohibition of adding ingredients.

- Prohibition of refilling containers.

- Prohibition to handle the product at the point of sale in a way other than indicated by the Responsible Person.

- Individual unit of sale packaging material description for which compatibility has been determined in the safety assessment.

- Description of the CPFP packaging process.

- Description of the labeling process for individual units of sale and model labels.

\subsubsection{With Regard to the Manufacturing and CPFP Packaging Process}

As stated in article 8 of Regulation 1223/2019 [2], in order to achieve high human health protection levels, the manufacturing of cosmetic products shall be carried out in accordance with the Good Manufacturing Practices (GMP) set forth in the UNE-EN ISO 22716 Standard [7].

As a result, in the manufacture of a CPFP, GMPs shall be applied during production, control, storage and until the product is dispatched by the manufacturer to the point of sale.

On the other hand, taking into account that CPFP will be packaged at the point of sale facilities, which do not fall within the scope of GMPs, it is necessary to take additional recommended measures in order to protect the quality and safety of the cosmetic product:

1. Containers should be fitted with a system to facilitate hygienic dispensing, minimizing the risk of product accumulation and reducing the risk of microbiological contamination. Depending on the type of product, replaceable nozzles or other systems may be used.

2. If CPFP containers are returned by the point of sale to the manufacturer, to be used continuously for the same formulation, a container cleaning procedure should be established, including the procedure, the products to be used and the cleaning expiry date.

3. Instructions and precautions for product handling and packaging at the point of sale should be provided to the point of sale to ensure that the product maintains the quality characteristics for which it was manufactured, as indicated in Section 3.1.1.

On the other hand, Spanish legislation establishes that, in accordance with article 17 of RD 85/2018 [4], material manufacturers of CPFF and importers shall submitted the corresponding Responsible Declaration of manufacturing or import activities to the AEMPS.

A Responsible Declaration is an administrative procedure through which material manufacturers and importers declare that they comply with the requirements and obligations inherent to the exercise of the activity and therefore the products they manufacture 
or import have been manufactured in accordance with the principles of Good Manufacturing Practices. This allows them to carry out the activity of manufacturing or importing cosmetics in Spain from the moment the declaration is submitted to the AEMPS; without prejudice to the powers of verification and ratification by the AEMPS after this submission.

\subsection{Recommendations to Be Taken into Account by Point of Sale}

\subsubsection{With Regard to CPFP Packaging}

Personnel performing the CPFP packaging activity shall follow the Responsible Person's instructions, paying particular attention to the following aspects:

1. CPFP storage conditions and shelf life (before and after opening) and of the individual units of sale.

2. CPFP and individual units of sale storage conditions.

3. Instructions for the performance of the packaging at the point of sale.

4. Hygiene rules to be observed at facilities (e.g., segregation of spaces), materials and personnel in the packaging at the point of sale operations.

5. Instructions for cleaning of nozzles or other packaging at the point of sale utensils and containers.

6. Indications that the CPFP should not be transferred to a container other than the individual unit of sale container.

7. Indications that no ingredients may be added to the CPFP, nor may it be subject to any handling at the point of sale, other than indicated by the Responsible person.

8. Description of the packaging material or which compatibility has been demonstrated by the Responsible Person. If the consumer decides to use their packaging without following these recommendations, it shall be at their own risk.

With regard to Spanish legislation, it should be noted that in accordance with the provisions of article 17 of RD 85/2018 [4], establishments that carry out the activity of packaging CPFP do not have to submit a responsible declaration of cosmetics manufacturing activities, as the CPFP is already a finished product.

3.2.2. With Regard to the Labeling at the Display Area and on the Individual Unit of Sale

Cosmetic products shall include the required information on their labeling, in accordance with article 19.1 of Regulation 1223/2009 [2], that is:

- Product name or reference identifying it

- Name and address of the Responsible Person

- Country of origin (if the product is imported)

- Nominal content

- Date of minimum durability

- Particular precautions to be observed in use

- Batch number

- Product function

- List of ingredients

Given that CPFP will be handled at the point of sale, they may not be labeled in the retail display area with the original labeling.

For this reason, the Responsible Person of the product shall ensure that consumers have all the required information, not only on the original CPFF packaging, but also in the display area and on the individual unit of sale.

If the original CPFP label is not visible at the public display area, a minimum of the following information shall be made visible:

- Product name or reference identifying it

- Name and address of the Responsible Person

- Particular precautions for use

- Product function

- List of ingredients 
- Country of origin if the product is imported.

This information may be provided by means of a sign in the product's immediate surroundings.

It is not critical that the nominal content and batch number are displayed, as this information does not influence the consumer's choice of products.

All required information shall be provided on the individual unit of sale without exception. The instructions for portioning and labeling provided by the Responsible Person must ensure traceability of batches, even if the batch number is not displayed in the display area.

\subsection{Technical Considerations}

All of the above recommendations should be applied based on a microbiological risk assessment of each product, taking into account the provisions of UNE EN ISO 29621:2011 [5] and UNE-EN ISO 17516:2014 [6]. These standards allow products to be classified as low microbiological risk or not, and establish the microbiological limits for the different types of products, respectively.

The AEMPS recommends that products for which stricter microbiological limits are established for their safety should not be packaged at points of sale, including products specifically intended for children under three years of age, the eye area or mucous membranes.

Furthermore, due to the wide variety of parameters to be taken into account to establish the stability of products packaged at the point of sale, and the technical complexity involved, it is recommended to considerably reduce the minimum shelf life of the product after handling, depending on its microbiological risk. As a general rule, it is advisable not to exceed three months, although this date may vary depending on each product's specific characteristics.

In order to transfer the conclusions obtained in this research to the general public, the "Instruction for the practice of cosmetic product packaging at the point of sale was prepared" [1].

\section{Discussion}

The Instruction [1] for the practice of cosmetic product packaging at the point of sale was approved by the CTI on 16 April 2021, and was published on the AEMPS website on 21 April.

Since publishing, the AEMPS has carried out a dissemination campaign at conferences held at different cosmetic industry venues:

- Committee for Cosmetic and Consumer Health (CD-P-COS) of the European Council

- Platform of European Market Surveillance Authorities for Cosmetics (PEMSAC) Group of the European Commission.

- 5th ERPA Annual Virtual Congress on Regulations and Compliance for Cosmetics (CRCC2021).

- $\quad$ 15th AEMPS Pharmaceutical Inspection Conference

- Regulatory update. Virtual Congress December 2021. National Association of Perfumery and Cosmetics in Spain (STANPA).

The instruction was also disseminated through social networks. As of 22 September 2021, data related to the number of views are as follows:

- Views on Twitter: 1593

- Views on LinkedIn: 4526

The available data on dissemination on social media show that the text has generated great interest, especially the high number of views of the text on LinkedIn, which is an eminently professional network.

The real impact of the publication cannot be assessed at this stage; it will be necessary to wait for a National Market Control Campaign that focuses on inspecting this type of establishments. 
Taking into account that the Instruction [1] includes in one single document all the recommendations and frame legislation on this practice, this document would help economic operators to comply with all the legal requirements and encourage this practice, promoting the safety of cosmetic products and consumer health.

\section{Conclusions}

One of the main conclusions of this article is that after the bibliographic review of the legal framework for cosmetic products at European and Spanish level, we can conclude that it is a legal practice.

The application of this Instruction [1] by the responsible persons, manufacturers and personnel at the point of sale, contributes to protecting consumers health which was one of the main of AEMPS objectives.

Despite the fact that we know that document had generated a great interest according to the social media data and our efforts to disseminate it in specialized forums, we cannot know the real impact of the publication because we do not have real data and it has passed a short period of time from its publication for its implementation. It would be necessary, in future, to perform a market surveillance campaign in order to obtain quantitative data.

On the other hand, the application of this Instruction [1] contributes to minimize the packaging waste, to enhance sustainability and to reduce environmental impact caused by the use of cosmetics products because it is associated with the containers reuse.

However, at the moment it is not possible to evaluate the real impact of the publication. This guidance supports the activity of packaging cosmetic products at the point of sale. If it is followed by the agents involved the products packaged at the point of sale will be safer for the consumers. Moreover, it will encourage the consumers to reduce de use of plastics and reuse containers. To quantify if it has generated a significant environmental impact it would be necessary to perform a market surveillance campaign.

Despite its limitations, from our point of view, the recommendations given in the Instruction [1] would be useful to economic operators interested in this practice not only in Spain, but also in other countries. As ensuring the safety of cosmetic products is a requirement for cosmetic products all over the world.

Finally, it should be emphasized that the Instruction [1] is the first and single European document, which develops recommendations about the packaging of cosmetic products at the point of sale activity supported by a Competent Authority.

\section{Glossary of Terms}

- Cosmetic product intended for packaging at the point of sale (CPFP): a cosmetic product that is packaged at the point of sale in accordance with a series of instructions provided by the Responsible Person, for example, a bar of soap that is divided into small pieces.

- $\quad$ Packaging at the point of sale: product handling at the point of sale through which the CPFP is divided into smaller units that are then acquired by consumers.

- Individual unit of sale: cosmetic product packaged at the point of sale purchased by the consumer.

- Point of sale: A place where the CPFP is packaged and the commercial transaction of the individual unit of sale is carried out, for example, a shop, a shopping center stall, etc.

- Responsible Person: a natural or legal person established in the European Union who ensures compliance with all the requirements set out in the Regulation, and whose name and address appear on the labeling of cosmetic products.

- Material manufacturer: a natural or legal person who carries out the activity of manufacturing the cosmetic product.

- Low microbiological risk products: cosmetic products whose compositional characteristics together with their production and packaging conditions, and a combination of 
these factors, do not promote the proliferation of undesirable microorganisms, as they create a hostile environment that does not allow growth and/or microbial survival.

- Technical Inspection Committee (CTI in Spanish): the coordinating body for the inspection and control of medicines, medical devices, cosmetic products responsible for ensuring the homogeneity of criteria and actions of the inspection and control services of the Spanish Agency of Medicines and Medical Devices (AEMPS) and the competent bodies of the Autonomous Communities (CCAA in Spanish). https: / /www.aemps.gob.es/laaemps / comites-tecnicos-de-la-aemps / comite-tecnico-de-inspeccion-cti/ (accessed on 12 January 2022)

Author Contributions: Conceptualization, B.B.G., A.L.P. and R.C.S.L.; methodology, B.B.G., A.L.P. and R.C.S.L.; investigation, B.B.G., A.L.P. and R.C.S.L.; resources, B.B.G., A.L.P. and R.C.S.L.; writingoriginal draft preparation, B.B.G. and A.L.P.; writing-review and editing, R.C.S.L.; supervision, R.C.S.L.; project administration, B.B.G. and A.L.P. All authors have read and agreed to the published version of the manuscript.

Funding: This research received no external funding.

Institutional Review Board Statement: Not applicable.

Informed Consent Statement: Not applicable.

Data Availability Statement: Not applicable.

Conflicts of Interest: The authors declare no conflict of interest.

\section{References}

1. TIC. Instruction on the Activity of Packaging at the Point of Sale of Cosmetic Products. Available online: https://www.aemps. gob.es/cosmeticos-cuidado-personal/docs/fraccionamiento-productos-cosmeticos.pdf?x21801 (accessed on 12 January 2022).

2. Regulation (EC) $N^{\circ} 1223 / 2009$ of the European Parliament and of the Council of the European Union, of 30 November 2009, on Cosmetic Products; OJ L 342; European Parliament and the Council of the European Union: Strasbourg, France, 2009 ; p. 59.

3. Royal Legislative Decree 1/2015, of 24 July 2015, Approving the Revised Text of the Law on Guarantees and Rational Use of Medicines and Medical Devices; BOE No. 177; Ministerio de Sanidad, Servicios Sociales e Igualdad de España: Madrid, Spain, 2015.

4. Royal Decree 85/2018, of 23 February, Regulating Cosmetic Products; BOE No. 51; Ministerio de Sanidad, Servicios Sociales e Igualdad de España: Madrid, Spain, 2018.

5. UNE EN ISO 29621:2011 Cosmetics. Microbiology. Guidelines for Risk Assessment and Identification of Products with Low Microbiological Risk; Asociación Española de Normalización y Certificación (AENOR): Madrid, Spain, 2011.

6. UNE-EN ISO 17516:2014 Microbiological Limits in Cosmetics; Asociación Española de Normalización y Certificación (AENOR): Madrid, Spain, 2014.

7. UNE-EN ISO 22716:2007 Cosmetic Products. Good Manufacturing Practices. Good Manufacturing Practice Guide; Asociación Española de Normalización y Certificación (AENOR): Madrid, Spain, 2007. 